\title{
O hibridismo genealógico: $O$ cego de Joaquim Manuel de Macedo
}

\author{
Fernanda Verdasca Botton*
}

\begin{abstract}
Resumo: Na tragédia grega, a figura do cego é comumente ligada à sabedoria e à agudeza de sentidos. Na peça teatral $O$ cego, de Joaquim Manuel de Macedo, entretanto, a ausência da visão física reúne em Paulo o subjetivismo romântico e o inexorável destino dos heróis trágicos. Além disso, no desenrolar da ação, a cegueira de Paulo trará aos demais personagens da trama outros princípios ligados ao drama e à tragédia clássica. Sendo assim, analisando os elementos constitutivos de $O$ cego, 0 presente artigo visa revelar o hibridismo genealógico presente na construção deste texto dramatúrgico de Macedo.
\end{abstract}

Palavras-chave: Tragédia. Drama. Macedo.

\section{Tragédia e drama.}

Segundo Décio de Almeida Prado, um dos pressupostos da tragédia é o modo como se constrói a ação:

\begin{abstract}
A ação empenhava sempre a história do ponto de vista culminante, já próximo ao desenlace: aqueles momentos de crise do herói, premido pelo precipitar dos acontecimentos, confrontado consigo mesmo, com os outros ou com o destino, revela finalmente a sua dimensão trágica. (1996, p. 170)
\end{abstract}

Em O cego, Joaquim Manuel de Macedo segue essa regra, colocando em cena ações que, em uma revolução solar, levarão Paulo ao encontro de seu destino trágico.

Cinco são os atos que compõem a peça - $A$ mãe do cego, $A$ noiva, $O$ sacrifício, Ciúme e $A$ noite de núpcias - e, apesar de somente o primeiro e os dois últimos estarem centralizados na figura de Paulo, todos os acontecimentos à cegueira dele se reportam. Sendo assim, tendo Paulo como sujeito principal de nosso estudo e partindo dele para o entendimento das outras personagens e da ação como um todo, pretendemos mostrar como Manuel de Macedo mescla no bojo de sua peça elementos da tragédia clássica e do drama romântico.

\footnotetext{
* Doutora pela USP. Professora da Fatec - Governo do Estado de São Paulo. E-mail: ferverdasca@gmail.com
} 
É comum encontrarmos nos teóricos do movimento romântico a oposição que este novo estilo fazia aos preceitos da literatura clássica; Victor Hugo assim o fez em seu Prefácio do Cromwell, Madame de Staël na obra Da Alemanha. À unidade de tom clássica, opunha-se o drama que unia a comédia à tragédia e o grotesco ao sublime. Ao homem que projetava sempre para fora a ação da alma, o homem devorado por suas próprias reflexões; ao herói que era sempre regido pelo destino, o que possuía a honra e o amor como ideais cavalheirescos a guiarem suas escolhas em busca da nobreza de alma.

Mesmo assim, particularmente no teatro, elementos trabalhados por Aristóteles como pertencentes à tragédia clássica - como o pathos, a hamartia, o destino (fatum) e a anagnórisis - eram explorados na ação de algumas peças classificadas como dramas românticos, dentre elas, $O$ cego, de Manuel de Macedo.

No Dicionário do Teatro Brasileiro, a peça em questão serve para exemplificar o verbete "drama romântico" que explora o seu tempo e a "cor local" e, na explicação dessa e de outras peças que seriam classificadas de tal maneira, temos a seguinte colocação:

O drama romântico é uma forma teatral que nasceu em oposição à tragédia clássica. Se nesta vigoram as regras impostas pela poética do Classicismo, naquele as regras são abandonadas em nome da liberdade de criação artística. (GUINSBURG; FARIA; LIMA, 2006, p. 17).

Estudando as personagens e o texto de $O$ cego, veremos que esta oposição tão clara na teoria é, em certos textos românticos, um amálgama que alguns escritores criam do que thes é antigo com o que lhes é contemporâneo.

\section{Os regentes da vida humana}

No amanhecer do dia de seu casamento, Paulo dialoga com seu servo Daniel. Em imagens oníricas, Paulo recorda a primeira vez que encontrara Maria. O canto melífluo e melancólico é a característica que precede a presença da amada. Ao trazer à lembrança outros traços dela, as palavras de Paulo nos descrevem uma mulher cuja beleza é tão perfeita que até o sol brilhante se enamora dos longos e negros cabelos que caiam "sobre níveas espáduas de alabastro", tão sublime que é capaz de perfumar "o deserto de seu hálito" (MACEDO, s.d., p. 4); ascética a tal ponto que ele a designa como uma "virgem de angélica pureza" (MACEDO, s.d., p. 16).

Dois anos após este primeiro encontro, Paulo ficara cego. Emília relata que a cegueira do filho é física, mas a ação do texto de Macedo cria uma ambiguidade quanto a isso. Como os acontecimentos nos revelam, paradoxalmente, apesar do amanhecer trazer as recordações de Maria, apesar dela ser considerada por Paulo como a luz de sua vida e sua "derradeira esperança" (MACEDO, s.d., p. 05); no canto da angélica figura ecoava, como saberemos no segundo ato, o sofrimento por amar Henrique, o irmão de Paulo. Sendo assim, cego também pela paixão, Paulo não compreendera que Maria amava outro e isso o levaria ao erro funesto: querer casar-se com a mulher anjo que romanticamente imaginara e por quem se apaixonara. 
Hamartia é a palavra grega para "o erro de julgamento e a ignorância que provocam a catástrofe" (PAVIS, 2003, p. 191). No texto de Macedo, Paulo cometeu a hamartia quando julgou que o canto de Maria era de um sentimento que estava por vir e não um amor já existente por outro.

Para Aristóteles (s.d., p. 258), o herói trágico "não é mau nem perverso, mas cai no infortúnio em consequência de qualquer falta". Paulo não tinha conhecimento de que a amada já era apaixonada por Henrique, não sabia do relacionamento dos dois e nem que o casamento para ela seria uma penitência. Contudo, ao enganar-se quanto ao amor de Maria, Paulo, tal qual um herói aristotelicamente trágico, comete a falha que o levará ao fado.

Emília tem maus presságios. No passado, ela orientara o filho para o casamento. Contudo, a cegueira física de Paulo evoca nela sentimentos terríveis que a fazem dizer três vezes: "(com acento doloroso, e como profético): Neste himeneu pressinto uma desgraça" (MACEDO, s.d., p. 06,07,31).

O leitor do texto poderia acreditar que Macedo realiza uma redundância ao utilizar os termos profético e pressentimento respectivamente na rubrica e na frase a ser dita pela mãe. Contudo, esta repetição grifa a importância que o título do primeiro ato - A mãe do cego - já havia proporcionado à personagem de Emília e aos pensamentos por ela emitidos.

Macedo constrói Emília como o oráculo trágico cuja finalidade é aconselhar o herói prevenindo-o ou guiando-o ao destino. No que concerne ao aviso, observamos que Emília ignora o amor que existe entre Maria e Henrique, mas sabe que os sentimentos de Paulo, sua angústia pela cegueira física e sua paixão por Maria, acordam nele a desconfiança e o ciúme. Quanto ao oráculo que guia ao destino, ao ouvir as palavras da mãe, inicia-se em Paulo uma desconfiança quando à lealdade de Maria, desconfiança esta que o levará a pensar em matá-la no quarto ato.

Essa ambiguidade da fala do oráculo é comum na tragédia clássica. Lembramos que em Édipo Rei o oráculo de Delfos previne Édipo que este matará seu próprio pai, unir-se-á em matrimônio à mãe e mostrará aos homens descendência impura. Mas, paradoxalmente, este aviso fará o herói fugir de Corinto e caminhar em direção à Tebas onde os males previstos ocorrerão.

Jean Pierre Vernant julga ser fulcral para o entendimento do trágico grego a compreensão de que os heróis daquele tempo não possuíam a categoria da vontade:

[...] Em que medida o homem [trágico] é realmente a fonte de suas ações? No próprio momento em que sobre elas o homem delibera em seu foro íntimo, elas não têm sua verdadeira origem em algo que não é ele mesmo? A significação delas não permanece opaca àquele que as empreende, uma vez que os atos tiram sua realidade não das intenções do agente, mas da ordem geral do mundo à qual só os deuses presidem? (2005, p. 23)

O trecho é pertinente para sabermos que, ao fugir das previsões do oráculo, Édipo pensa seguir sua vontade, mas nada mais faz do que ser um títere do destino. 
Semelhante aos heróis trágicos, Paulo não ouve os conselhos de sua mãe e persiste na ideia de casar-se com Maria. Para ele, ser cego é ser "desgraçado" (MACEDO, s.d., p. 08) e a amada seria o bom anjo que o salvaria da infelicidade. Entretanto, pensando ter escolhido o caminhar em direção à ventura, Paulo, na verdade, encontrará no himeneu a cegueira sentimental do ciúme, cegueira que lhe guiará ao inexorável infortúnio trágico.

Emília falará três vezes a Paulo que ela pressente uma desgraça no casamento do filho.

Para salientar esse estigma do herói, abundam no início e no final do texto de Macedo expressões e frases: "eu terei sempre da dor o fel no néctar dos prazeres", "meu mal é seu remédio", "infernal vida", "Oh! Desgraçado", "o futuro de um homem desgraçado", "O mundo?!!! É um demônio multiforme [...] é sereia que canta enganadora,/ Crocodilo que chora traiçoeiro,/Lobo que assalta, tigre que devora/Ou leopardo que surpreende a vítima!...", "Meu tálamo há de ser sepultura", "Sem poder ser feliz, faço o infortúnio/Daqueles a quem amo! Oh! Sorte iníqua!/A minha vida é um muro insuperável [...]" (MACEDO, s.d., respectivamente p. 3, 3, 7, 8, 24, 32, 33 e 40).

Atentamos para o fato de que o adjetivo "desgraçado" e seu uso no gênero feminino são também utilizados para qualificar duas outras personagens, Henrique e Maria. Etimologicamente, esse vocábulo é formado por dois elementos: "des" (prefixo de negação) e "graça" (palavra comumente utilizada no cristianismo para expressar o dom ou virtude concedidos por Deus como meio de salvação). Sendo assim, Paulo, Henrique e Maria são qualificados como pessoas das quais foram retiradas as possibilidades da salvação cristã.

Observemos outros elementos do enredo, para melhor compreender a importância que a palavra "desgraçado" e seu significado católico adquirem em nossa análise.

No primeiro ato, como já estudamos, Paulo se recorda do canto e da imagem de Maria em um "sonho visão que se evapora" (MACEDO, s.d., p. 04). Perfumada, de brancas vestes, com um sorrir que é capaz de fazer a natureza por ela apaixonar-se, Maria seria a mulher anjo do Romantismo cristão que, na mente de Paulo, é profícua de "graças".

Todavia, se os atos subsequentes mostram que o dom da beleza e da virtude se confirmam em Maria, as palavras revelam que a ela não foi concedida a dádiva da felicidade.

Em um monólogo patético, $A$ noiva verte lágrimas sentidas por um "sonho de venturas" (MACEDO, s.d., p. 10) perdido: tendo a fonte como altar e o vale como templo, ela prometera amar Henrique, mas agora terá de marchar ao sacrifício do casamento com Paulo.

Eu me curvo ao destino de meu sexo;

É preciso viver no nosso mundo;

Receber como leis suas cadeias;

Ter o riso no rosto, e o pranto n'alma,

E dizer - sou feliz!... - Que sorte iníqua! 
É a mulher excepcional vivente, Que tem na alma, e não querem que ela sinta! Tem coração e ordenam que não ame!... Sujeita desde que nasce até que morre, De pai passa a tutor, irmão e marido...

Sempre um senhor... (o nome é que se muda) [...]

Criança, junto a quem sempre vigiam;

Cego, que sempre pela mão se leva;

Eis a mulher!... Eis o que sou, e todas!... (MACEDO, s.d., p. 10)

Destacamos no trecho anterior duas informações: a de que o "destino" do sexo feminino é curvar-se à decisão de homens e a de que, por isso, a mulher (sexo feminino) sempre será como um cego guiado por outrem (sexo masculino).

Amando Henrique, Maria Ihe prometera fidelidade eterna. Mas a decisão de cumprir ou não com a palavra não cabe à filha e sim ao pai. Damião, tendo Henrique como morto na guerra, promete Maria em casamento a Paulo. Cumprir a palavra que pelo pai (masculino) foi dada é então para Maria (feminino) dever superior. Ou seja, para Macedo, na sociedade burguesa do século XIX, é destino atribuído às mulheres serem submissas às decisões dos homens. Serem guiadas, portanto, como cegos, pelos homens.

Filho do Caos e da Noite, na mitologia grega o Destino é um deus que tem debaixo dos pés o globo terráqueo e nas mãos a urna fatal que encerra a sorte dos mortais.

Percebemos que Maria utilizou a palavra destino para se referir ao sofrimento em que foi lançada. Contudo, mais do que o destino estabelecido por um deus mítico, Maria segue conceitos estabelecidos pelo "deus" sociedade burguesa de seu tempo. Portanto, podemos encontrar na colocação de Maria um amálgama do pensamento trágico com o burguês. Contudo não podemos atribuir somente a um destino o futuro infeliz de Maria. Se Henrique tivesse firmado compromisso antes de ir para a guerra, se não houvesse 0 engano de 0 acreditarem morto, se Paulo não cometesse a hamartia de a pedir em casamento, ela, mesmo mulher, poderia ter tido outro futuro que não o da sorte iníqua.

Assim, maculada para a infelicidade, Maria sofre não apenas por ser mulher, mas também por ter os fios de sua existência como que enrolados pela trágica parca Láquesis ${ }^{1}$.

No segundo ato, Maria realiza um solilóquio em que termos aparentemente antagônicos são utilizados como pertencentes a um mesmo pensamento.

\section{[...] Doce momento!}

Tão veloz como um sonho de venturas,

Ao qual seguiram dias de infortúnio

Tão longos como a vida que me pesa. [...]

\footnotetext{
${ }^{1}$ Segundo o pensamento mítico, quem executa as ordens do impiedoso deus Destino são as três fiandeiras da vida humana: Cloto (que segura a roca dos fios de seda ou cânhamo), Láquesis (que dá a volta ao fuso no qual os fios se enrolam) e Átropos que inspeciona o trabalho e corta o fio fatal na hora da morte.
} 
Marchemos com valor ao sacrifício.

É da mulher a história em sofrimentos

Fértil. Nem será este o derradeiro!...

Eu me curvo ao destino de meu sexo [...]

$E$, portanto, eu serei como mil outras

Mártires nobres. [...] (MACEDO, s.d., p. 10,11)

Ao relacionar as diferenças existentes entre Classicismo e Romantismo, podemos observar que enquanto no primeiro os homens possuem reminiscências do paganismo e julgam-se dependentes do destino, no segundo, o cristianismo coloca nas mãos dos homens aquilo que Vernant designa como "vontade" (designado pelo cristianismo de livre-arbítrio).

No discurso de Maria, entretanto, enquanto a personagem fala da peripécia trágica de uma mulher que vive na felicidade momentânea e encontrará com seu infortúnio fatídico, palavras como "destino" (cujo sujeito da vontade é o divino) e "sacrifício" (cujo sujeito é o próprio ser) se complementam. Portanto, o pensamento trágico pagão de subserviência aos deuses e o romântico cristão de possibilidade de escolha, como estudaremos com propriedade em momento azado, misturam-se na construção dessa peça de Macedo.

No quinto ato, quando julga ter perdido o amor de Maria e anela a morte, Henrique também se designa como "desgraçado" (MACEDO, s.d., p. 37).

Quem primeiro constrói o retrato de Henrique é Paulo. Para o cego, ele é o irmão que não fora "surdo à voz da pátria" (MACEDO, s.d., p. 06) e tomara as armas com o intuito de batalhar bravamente pela independência. No segundo ato, as palavras de Maria confirmam o que fora dito por Paulo. Aos olhos da amada, Henrique é nobre guerreiro que foi lutar pela honra de seu país.

No peito, o herói da pátria carrega como marcas de seu denodo uma cicatriz que lembra o ferimento que quase o matou e uma medalha de guerra. Em sua conversa com a mãe, Henrique explica o que Ihe ocorrera no exílio: em uma batalha sofrera "um golpe profundo" (MACEDO, s.d., p. 18). Nos dias posteriores, o sangue the fugira a tal ponto que o acreditaram morto, mas ele se reanimara e pudera ainda ferir com golpe fatal os inimigos do Brasil.

Segundo Guinsburg e Rosenfeld (1978), opondo-se à arte atemporal e inespacial dos Clássicos, o herói romântico está inserido em um tempo e assume as dores de sua terra natal quando, encarnando uma vontade antes social do que pessoal, vê-se como um ser histórico.

Como herói romântico, Henrique ouvira o chamado da pátria e lutara na guerra do Prata contra a Argentina. Contudo, mais do que narrar detalhadamente a guerra que causara as marcas da coragem no peito de Henrique, mais do que fazer uma peça romântica a defender o herói como ser histórico, Manuel de Macedo vê na batalha o fato que afastara Henrique de sua amada e trouxera o sofrimento amoroso que, no coração de suas personagens, instalara-se. 
Ou seja, na escrita de Macedo a guerra pela pátria serve como mote para construir o herói Henrique, mas o que faz a personagem sofrer é, quase que melodramaticamente, o exacerbado sentimentalismo amoroso.

Salientamos que, em grego, drâma significa ação e como esta se afigurava exclusiva no teatro, passou a ter esse significado específico na época clássica. No século XVIII, entretanto, com a peça Entretiens sur le fils naturel (1757), o termo passa a ser utilizado também nas conotações que assumiria no Romantismo: "peça híbrida entre cômica e trágica" e texto teatral que substitui "personagens da história greco-romana por cidadãos burgueses do tempo, divisados no seu habitat próprio e nas condições peculiares à sua classe social" (MOISÉS, 2002, p. 162).

Em 1772, seguindo a liberdade cunhada pelos românticos, Rousseau acrescentou ao drama a musicalidade da ópera italiana e designou sua peça Pygmalion de melodrama.

Em 1800, os textos de Pixérécourt, autor conhecido pelos franceses como "/e père du mélodrame" (ESTÈVE, 1923, p. 139), estabeleceram outros elementos que iriam compor o melodrama. Apresentando tonalidades sentimentais excessivas, acompanhadas ou não pela música, e uma visão maniqueísta do mundo burguês, os textos de Pixérécourt trabalham com signos que conotam hiperbolicamente e à exaustão o embate entre Bem e Mal. Como clichês ${ }^{2}$ a representarem este embate, personagens virtuosas são perseguidas por tiranos; mutilações e mortes sangrentas explicitam os interesses financeiros; cartas revelam parentescos insuspeitos; mulheres enlouquecem e entoam xácaras melódicas; a vingança é exigida para dirimir injustiças; frases grandiloquentes são ditas em tom moralizador, e, no final, a derrota do Mal e a explícita vitória redentora da virtude mostram que o puro amor sempre vence a tirania.

No texto de Macedo, além de elementos da tragédia clássica e do drama romântico, alguns clichês melodramáticos podem ser identificados.

Herói nacional, Henrique tem no peito a cicatriz de guerra que lhe deu uma medalha por bravura. Entretanto, a ferida pela luta patriótica não será tão explorada por Macedo quanto a do exacerbado sentimentalismo que Henrique possui.

No terceiro ato, perto da hora do himeneu, Henrique, mesmo com a "paixão nas asas", deseja sinceramente que "Deus faça feliz Paulo". Ao falar com Maria, entretanto, sente "ardendo dentro do coração o fogo do inferno" e a acusa de "perjura", de mulher em cujos lábios sempre "há mentira", de "pérfida" capaz dos mais vis sacrilégios. Neste mesmo ato, Henrique saberá que Damião é quem obrigara Maria a casar-se; tomado pela indignação, Henrique chama o pai da amada de "Tirano!!!" e pede que Deus seja capaz de fulminar a "prepotência [deste] Bárbaro velho [...] que atormenta a própria filha" (MACEDO, s.d., respectivamente p. $19,19,20,20,21,21,23$ e 23$)$.

Apesar dos excessos sentimentais, Henrique não personifica o Bem maniqueísta melodramático, pois, após saber da inocência de Maria, inveja a sorte do irmão e, desejando ter a amada como amante, declara: "Não tenho, não, a força da virtude" (MACEDO, s.d., p. 36).

${ }^{2} \mathrm{O}$ termo clichê é comumente utilizado para definir os elementos que se repetiram à exaustão no melodrama. 
Para fugir do possível adultério, Henrique decide voltar à guerra. Antes da partida, todavia, encontra-se com Maria para contar-Ihe a decisão. No encontro do casal apaixonado, Paulo, o herói trágico de até então, começa a assumir ares da maldade melodramática. Desconfiando da amada e do irmão, Paulo sente um "desejo insaciável de vingança!" (MACEDO, s.d., p. 28), desejo tão excessivo, que as seguintes imagens lhe vêm à mente:

\author{
Hei de sentir seu corpo convulsando \\ Preso entre as unhas enterradas \\ No colo vil!... O cheiro de seu sangue \\ Não me fará horror... E quando frio \\ Eu somente apertar cadáver torpo, \\ A um canto o arrojarei qual fardo inútil!!! \\ E depois... Para mim, Deus! O teu raio!... (MACEDO, s.d., p. 29)
}

Contudo, como suas ações do primeiro ato eram de um herói trágico, como seus atos são atribuídos não a uma maldade, mas sim ao fato de Paulo ser um títere do destino, a ele também não podemos atribuir o maniqueísmo próprio do melodrama.

Traços do melodrama ainda poderiam ser vistos na construção da personagem de Damião, uma vez que, no final do enredo, Henrique, que já o havia acusado de "Tirano" (MACEDO, s.d., p. 23), atribui-Ihe todos os infortúnios e o acusa: "Eis o fruto, senhor, da prepotência" (MACEDO, s.d., p. 40). Todavia, mesmo que Henrique melodramaticamente atribua a Damião as infelicidades sofridas, esta personagem deve ser analisada com mais acuidade.

Na cena II do segundo ato, após encontrar Maria em chorosas lamentações, o pai Ihe diz que ela sofre por "males fictícios" e Ihe pergunta: "Onde estão os tiranos que te oprimem?" (MACEDO, s.d., p.11). Maria poderia acusar ao pai pelos males sofridos, contudo, chamando-o de amigo e também de senhor, ela acaba atribuindo a culpa ao destino.

Além disso, Henrique cometera a hamartia de não firmar compromisso oficial com Maria antes de partir para a guerra e Damião, acreditando-o morto, concedeu a mão da filha, por desejo dela, a Paulo. A palavra empenhada é de extrema importância para Damião já que, como ele mesmo declara, não poderia macular um nome que dos avós e dos pais herdara sem mancha. Portanto, Damião cobra de Maria que a palavra seja cumprida, mas Maria é quem firmara o compromisso.

Sendo assim, os homens do texto de Macedo, apesar de exercerem ações melodramáticas, não podem ser codificados como o Bem ou o Mal do melodrama. Antes, são manifestações de verdadeiros personagens do drama romântico: "complexo, heterogêneo, múltiplo, composto de todos os contrários, mescla muito de mal e de muito bem, cheio de gênio e de mesquinhez [...] grotesco e sublime enfim" (HUGO, 1988, p. 75).

Ao contrário do que ocorre na tragédia, onde as ações da alma são projetadas para o exterior, na peça de Macedo as personagens masculinas são de tal modo devoradas pelo subjetivismo romântico que chegam a se assemelhar à construção sentimental do melodrama. 
Quanto a Maria, mais do que fruto do maniqueísmo, devemos vê-la como mulher romântica que é idealizada pelo amado, mas é cindida entre o amor oficial - a ser aceito por uma obrigação de manter-se fiel à palavra empenhada pelo pai - e o verdadeiro amor.

Lembramos, contudo, que alguns clichês melodramáticos também estão presentes nas ações de Maria. Na primeira cena da peça de Macedo, a melodia (melos do drama) pode ser ouvida quando a personagem de Maria entoa um canto melífluo de amor; canto que retorna no final do primeiro ato como "gemido" e "hino" (MACEDO, s.d., p. 10) ao anjo da saudade. Além disso, ela é capaz de sacrificar-se para diminuir a tristeza de Paulo, mesmo que para isso tenha que ouvir acusações de Henrique ou tenha que enlouquecer entoando xácaras ("Dizei: lá vai a louca em desvarios!/ Quando eu cantar festivos doces hinos,/ Dizei..." (MACEDO, s.d., p. 14)). Por fim, por amar e ter essa paixão como um bem que nunca se concretizará, seus solilóquios são repletos da tonalidade sentimental exagerada que ecoa no melodrama ("Sim eu hei de saber [...] / Abafar meus suspiros e gemidos/ E esconder os tormentos de minh'alma/ desse mundo egoísta e sem piedade [...] (momento de doloroso silêncio, depois ela se desfaz em pranto, e exclama;) Adeus, meu vale!!! Adeus, ó minha fonte!!!" (MACEDO, s.d., p. 11)).

Destarte, apesar de clichês melodramáticos serem facilmente identificáveis em O cego, Macedo não constrói um melodrama, pois, ao invés de atribuir a infelicidade a um tirano melodramaticamente maniqueísta - como o faz Henrique - Maria, Paulo e as demais personagens a tem como fruto de dois elementos ideologicamente antitéticos: o destino que é atribuído aos homens (cerne da tragédia grega) e o martírio que é escolhido pelos homens cristãos (elemento primordial de vários dramas).

Para melhor compreendermos este antagonismo - essencial na diferença entre o trágico e o romântico - é necessário examinar o pensamento de dois filósofos que teorizaram o livre-arbítrio: Pico della Mirandola e Santo Agostinho.

Em 1486, o humanista italiano Giovanni Pico della Mirandola, no texto intitulado Discurso sobre a dignidade do homem (2001), narra como o Deus católico concedeu ao ser humano o livre-arbítrio. Segundo Mirandola, o homem possui um lugar muito especial dentro da criação e este fato estaria indicado nas próprias palavras das Escrituras que atestam ter sido o homem o único feito à imagem e semelhança do criador. Assim, narra o humanista, após "o sumo Pai, Deus arquiteto" ter criado o mundo com perfeição, não encontrou bem maior a ser dado àquele que era sua imagem e semelhança do que a capacidade de escolher. Desta forma, explica Pico della Mirandola, Deus, colocando o primeiro ser humano

[...] no meio do mundo, falou-Ihe desse modo: Ó Adão, não te demos nem um lugar determinado, nem um aspecto que te seja próprio, nem tarefa alguma específica, a fim de que obtenhas e possuas aquele lugar, aquele aspecto, aquela tarefa que tu seguramente desejares, tudo segundo o teu parecer e a tua decisão. A natureza bem definida dos outros seres é refreada por leis por nós prescritas. Tu, pelo contrário, não constrangido por nenhuma limitação, determiná-la-ás para ti, segundo o teu arbítrio, a cujo poder eu te entreguei. Não te fizemos nem celeste nem terreno, nem mortal nem imortal, a fim de que tu, árbitro e soberano artífice de ti mesmo, te plasmasses e te informasses, na forma que tivesses seguramente escolhido. Poderás degenerar até aos seres que são bestas, poderás regenerar-te até às realidades superiores que são divinas, por decisão do teu ânimo. (MIRANDOLA, 2001, p. 52). 
Sendo assim, enquanto o homem da antiguidade clássica estava sujeito ao destino que Ihe fora traçado pelos deuses e, mesmo quando julgava esboçar sua vontade, na verdade só confirmava sua subserviência, o homem da era católica, segundo o humanista do século $\mathrm{XV}$, recebeu de seu Deus o livre-arbítrio para degenerar-se (sendo grotesco como as bestas) ou regenerar-se (sendo sublime como os divinos).

Essa visão de livre-arbítrio é utilizada por vários escritores românticos, dentre eles citamos o próprio Hugo que, em Cromwell, tem o herói oscilando, pelas escolhas que realiza, entre ser grotesco (tirano da Europa, político pedante e fanático regicida) e ser sublime (sofredor torturado pela sua jovem filha, poeta e visionário). Observamos que Oliver é duplo e, sendo assim, suas escolhas nem sempre são antitéticas, mas em um Jean Valjean ou em um Arcediago Claude Frollo o livre-arbítrio da regeneração e a degeneração são mais claros.

Advertimos, contudo, que outro pensamento acerca do livre-arbítrio existe no mundo cristão. Entre 394 e 395 da era Cristã, Santo Agostinho terminou a obra intitulada $O$ livre-arbítrio. O texto patrístico em questão tem como tema exortar a bondade divina de ter concedido ao homem a capacidade de decidir seus caminhos. Além disso, observando a existência do mal na humanidade de sua época, Agostinho também quer provar que é culpa do homem a punição pelos erros cometidos uma vez que este é quem escolheu pecar.

No capítulo 18 da terceira parte do referido texto, dentre as razões que explicam o porquê da escolha errônea feita pelo homem, o filósofo salienta que a expulsão de Adão e Eva do Paraíso já mostrou "[...] a natureza corpórea ser de grau inferior à natureza espiritual.". Além disso: "[...] quando a vontade - esse bem médio - adere ao Bem imutável, o qual pertence a todos em comum, e não é privativo de ninguém, [...] quando a vontade adere ao Sumo Bem, então o homem possui a vida feliz." (AGOSTINHO, 1995, p. 135)

Trazemos ainda um trecho de Russel (1957) que será de suma importância para compreendermos o hibridismo genealógico existente na peça $O$ cego: a teoria da predestinação.

\begin{abstract}
Santo Agostinho ensinou que Adão, antes da queda, tinha livre vontade e teria podido abster-se do pecado. Mas como ele e Eva comeram a maçã, a corrupção entrou neles e passou a toda a sua descendência, de modo que ninguém, pelos próprios poderes, pode abster-se do pecado. [...] Mas, pela livre graça de Deus, certas pessoas [...] são escolhidas para ir para o céu; estes são os eleitos. Não vão para o céu porque são bons; todos nós somos inteiramente depravados, exceto quando a graça de Deus, que só é concedida aos eleitos, nos permite ser de outra maneira. (RUSSEL, 1957, p. 69).
\end{abstract}

O pensamento agostiniano anteriormente exposto invalidaria o livre-arbítrio e, por ser considerado herético, foi combatido pelo pensamento ortodoxo da Igreja católica.

Na mitologia da Antiguidade Clássica, a parca Cloto é a responsável por escolher a qualidade de fio que prenderá a roca que representa a vida humana: de seda e ouro 
para os homens cuja existência há de ser feliz, e de lã e cânhamo para todos aqueles que são destinados à infelicidade.

Segundo a predestinação agostiniana, Adão e Eva tiveram o livre-arbítrio de decidirem seus caminhos, mas, porque eles pecaram, os demais homens dependem da graça de Deus para serem salvos (se eleitos pelo divino) ou condenados.

Uma proximidade entre o homem sujeito aos deuses trágicos e aquele que está sujeito ao Deus católico agostiniano pode ser, portanto, detectada.

As filosofias retratadas permitem que entendamos como Paulo, Maria e Henrique invocam tantas vezes o nome de um Deus católico que é capaz de lhes arbitrar, à feição dos deuses pagãos, um destino "desgraçado". Mas, também permitem que entendamos o sacrifício e o martírio escolhidos por Maria, Henrique e, no suicídio, por Paulo.

Ao utilizarem o livre-arbítrio humanista, Maria e Henrique mostram que se eles acreditam em Deus agostinianamente, acreditam também, romanticamente, que a honra e o amor são ideais a serem almejados pelas almas nobres.

O final da peça de Macedo não nos diz se Maria e Henrique, por se plasmarem sofredores, terão como futuro a felicidade.

Quanto a Paulo, a ação de cometer o suicídio pode ser vista como a de um Édipo que se cega por entender que não podemos enganar o inexorável Destino, mas também pode ser a de um homem que cego pelas Parcas - fisicamente e sentimentalmente na paixão e no ciúme - vê que o verdadeiro Éden não está na mulher anjo, mas sim em uma salvação celestial.

Para compreendermos esse sentido romanticamente católico do suicídio, salientamos que somente o primeiro e o último ato têm como cenário um bosque. Além disso, se no início do enredo Paulo procura a salvação em Maria, mulher anjo prolongamento da natureza, no final saberá que a redenção romântica somente ocorre na morte como negatividade.

Na arte romântica, [...] a morte é apenas um perecer da alma natural e da subjetividade finita, um perecer que somente procede negativamente contra 0 negativo em si mesmo, que preserva o verdadeiro e, por isso, proporciona ao espírito a libertação da sua finitude e ruptura, bem como a reconciliação espiritual do sujeito com o Absoluto. Para os gregos, só a vida, unida à existência natural, exterior, própria deste mundo, era afirmativa, e a morte, por essa razão, a mera negação, o fim da realidade imediata. Mas na concepção de mundo romântica, a morte tem o significado da negatividade, isto é da negação da negação, e por isso, transforma-se tanto numa afirmativa, como num ressurgimento do espírito a partir da sua mera naturalidade e finitude inadequada. A dor e a morte da subjetividade agonizante convertem-se em regresso a si, em satisfação, bem-estar, e nessa existência afirmativa e reconciliada que o espírito somente pode atingir mediante a cessação da sua existência negativa, na qual ele está isolado da sua verdade e da sua vida reais. (HEGEL apud GOMES, 1992, p. 138).

Destarte, enquanto na tragédia grega os homens têm seus caminhos tecidos por Parcas guiadas pelo deus Destino, em $O$ cego, a infelicidade do herói pode lhe (e nos) parecer somente trágica, mas é também um martírio terreno impingido a alguns homens, quiçá àqueles que serão recolhidos no Éden da vida eterna cristã. 


\section{Unidades e diversidades}

Dentre as unidades da tragédia, Macedo utiliza a de tempo e a de tom em sua peça $O$ cego. Em uma revolução solar - do amanhecer do dia até a Noite de núpcias Paulo, Maria e Henrique se deparam com fios de cânhamo pressagiados tragicamente por Emília.

Na peça, não há um personagem cômico, mas o grotesco e o sublime - se não são gêneros a se amalgamarem - são caracteres que constroem as personagens complexas e heterogêneas. Tão complexas que para elas ainda ecoam no cristianismo elementos do paganismo clássico.

Confundidas pelas parcas trágicas ou agostinianas (que tecem as cegueiras de Paulo e Maria) e pelo livre arbítrio humanista (que permite a Henrique, Maria e Paulo serem cordeiros de um sacrifício), as personagens de Macedo mostram, ao cabo, existir um possível hibridismo entre a tragédia e o drama.

Acrescentamos ainda que, na finitude da vida terrena de Paulo, a peça possibilita duas visões: a trágica, que tem a existência como positiva e a morte como negativa, e que vê como correto presságio de Emília; e a romântica que tem a morte como negatividade e compreende o final do texto como a redenção cristã.

Além disso, como anagnórisis romântica a ser revelada a Paulo no final do texto, não temos a subserviência ao deus Destino, mas sim a revelação romântica de que contra o verdadeiro amor das almas sublimes, almas que choram ao saber que serão separadas, nada pode existir.

$\mathrm{Na}$ prosa poética de Macedo poderia reverberar, portanto, as palavras de Gonçalves de Magalhães: "Em não sigo nem o rigor dos clássicos, nem o desalinhos dos românticos, não vendo verdade absoluta em nenhum dos dois sistemas, faço as devidas concessões a ambos; ou antes, faço o que entendo e o que posso." (MAGALHÃES, 1970, p. 04).

\section{Bibliografia}

AGOSTINHO, Santo. O livre-arbítrio. Trad. de Nair de Assis Oliveira. São Paulo: Paulus, 1995.

ARISTÓTELES. Arte retórica e Arte poética. Trad. de Antônio Pinto de Carvalho. Rio de Janeiro: Ediouro, s.d.

BULFINCH, Thomas. O livro de ouro da mitologia. Trad. de Luciano Alves Meira. São Paulo: Martin Claret, 2006.

ESTÈVE. Edmond. Études de littérature préromantique. Paris: Librarie ancienne édouard champion, 1923.

GUINSBURG, J.; FARIA, João Roberto; LIMA, Mariângela Alves de. Dicionário do Teatro Brasileiro. São Paulo: Perspectiva, 2006. 
GUINSBURG, J; ROSENFELD, Anatol. O romantismo. 4. Edição. São Paulo: Perspectiva, 1978.

HEGEL. A morte no romantismo. In: GOMES, VECHI. A estética romântica. Trad. de Maria Antônia Simões Nunes. São Paulo: Atlas, 1992. p. 138-139.

HUGO, Victor. Do grotesco e do sublime. Trad. e notas de Célia Berretini. São Paulo, Perspectiva, 1988.

MACEDO, Joaquim Manuel. O cego. Belém: Unama - Universidade da Amazônia, s. d. MAGALHÃES. Gonçalves de. Antonio José ou o poeta da inquisição. São Paulo: USP, 1970.

MIRANDOLA, Giovanni Pico della. Discurso sobre a dignidade do Homem. Trad. de Maria de Lurdes Dirgado Ganho. Lisboa: Edições 70, 2001.

MOISÉS, Massaud. Dicionário de termos literários. 11. Edição. São Paulo, Cultrix, 2002.

PAVIS, Patrice. Dicionário de teatro. Trad. sob a direção de J. Guinsburg e Maria Lúcia Pereira. 2. Edição. São Paulo: Perspectiva, 2003.

PRADO, Décio de Almeida. O drama romântico brasileiro. São Paulo: Perspectiva, 1996.

RUSSEL, Bertrand. História da Filosofia Ocidental. Tomo 2. Trad. de Brenno Silveira. São Paulo: Companhia Nacional Editora, 1957.

VERNANT, Jean-Pierre; NAQUET, Pierre Vidal. Trad. de Anna Lia A. de Almeida Prado, Filomena Yoshie Hirata Garcia e Maria da Conceição M. Cavalcante. Mito e tragédia na Grécia antiga. São Paulo, Perspectiva, 2005.

VICTORIA, Luiz A. P. Dicionário de Mitologia. Rio de Janeiro: Ediouro, 2000.

Title: The genealogical hybridity: O cego, by Joaquim Manuel de Macedo.

Abstract: In Greek tragedy, the blind character is commonly linked to wisdom and the acuteness of the senses. In the play O cego, by Joaquim Manuel de Macedo, however, the lack of physical sight gathers in Paul romantic subjectivism and the inexorable fate of tragic heroes. Beyond that, in the course of action, Paul's blindness will bring to the other characters, further principles related to drama and classical tragedy. So, analyzing the components of $\mathrm{O}$ Cego, this article aims at revealing the genealogical hybridity that appears in the construction of this dramaturgical text by Macedo.

Keywords: Tragedy. Drama. Macedo.

Recebido em: 26/06/2013. Aceito em 30/11/2013 